\title{
IMPLEMENTASI MEDIA PEMBELAJARAN BERBASIS ANDROID TERHADAP HASIL BELAJAR BAHASA INDONESIA
}

\author{
Url Jurnal: https://uia.e-journal.id/akademika/article/1311 \\ DOI : https://doi.org/10.34005/akademika.v10i01.1311
}

Submitted: 2021-04-07

Reviewed: 2021-04-20
Published: 2021-05-30

\author{
Kasman \\ Universitas Muhammadiyah Makassar \\ kasman@unismuh.ac.id
}

\begin{abstract}
The purpose of this study was to determine the effect of the implementation of Android-based learning media on students' learning outcomes of Indonesian at SMA Muhammadiyah Unismuh Makassar. The method used in this research is quantitative descriptive research method. The population in this study were all students at SMA Muhammadiyah Unismuh Makassar as many as 388 students. The sample in this study was 49 students. The data collection instruments used in this study were questionnaires and tests. The data analysis technique used in this research is quantitative descriptive analysis using the product moment correlation formula. The results showed that the $r$-count value, which is 0.998 , is greater than the rtab, which is 0.281 , so the alternative hypothesis $(\mathrm{Ha})$ is accepted and nil (Ho) is rejected. The results showed that if the Android-based media was used according to the portion needed in the learning process and following the instructions from the educator, in this case the teacher of the Indonesian Bahasa subject, it would have a positive impact on student learning outcomes. It can be concluded that there is a significant influence between the implementation of androidbased learning media with the learning outcomes of Indonesian students at SMA Unismuh Makassar.
\end{abstract}

Keywords: Android Learning Based Media; Learning Outcomes

\begin{abstract}
Abstrak: Tujuan penelitian ini adalah untuk mengetahui pengaruh implementasi media pembelajaran berbasis android terhadap hasil belajar Bahasa Indonesia siswa di SMA Muhammadiyah Unismuh Makassar. Metode yang digunakan dalam penelitian ini adalah metode penelitian deskriptif kuantitatif. Populasi pada penelitian ini adalah seluruh siswa di SMA Muhammadiyah Unismuh Makassar sebanyak 388 siswa. Sampel pada penelitian ini sejumlah 49 siswa. Instrumen pengumpulan data yang digunakan pada penelitian ini yaitu kuesioner (angket) dan tes. Teknik analisis data yang digunakan dalam penelitian ini adalah analisis deskriptif kuantitatif menggunakan rumus korelasi product moment. Hasil penelitian menunjukkan nilai $\mathrm{r}_{\text {hit }}$ yakni 0,998 lebih besar daripada $r_{\text {tab }}$ yakni sebesar 0,281 maka hipotesa alternatif (Ha) diterima dan nihil ( $\mathrm{Ho}$ ) ditolak. Hasil penelitian menunjukkan jika media berbasis android digunakan seseuai dengan porsi yang dibutuhkan dalam proses pembelajaran dan mengikuti intruksi dari pendidik dalam hal ini guru mata pelajaran Bhaasa Indonesia, maka akan berdampak positif pada hasil pembelajaran siswa. Hal ini dapat disimpulkan bahwa ada pengaruh yang signifikan antara implementasi media pembelajaran berbasis android dengan hasil belajar Bahasa Indonesia siswa di SMA Unismuh Makassar.
\end{abstract}

Kata Kunci : Media Pembelajaran Berbasis Android; Hasil belajar 


\section{PENDAHULUAN}

Dunia pendidikan tidak terlepas dari proses pembelajaran yang meliputi guru, siswa, dan lingkungan pembelajaran yang saling mempengaruhi satu sama lain dalam rangka tercapainya tujuan pembejaran. Media merupakan salah satu faktor penunjang tercapainya tujuan pembelajaran. Hal ini berkaitan dengan penggunaan media yang tepat dan bervariasi dalam proses pembelajaran dapat meningkatkan motivasi belajar dan dapat mengurangi sikap pasif siswa di SMA Unismuh Makassar yang ditunjukkan dengan berbagai kegiatan diluar materi pembelajaran yang disajikan yaitu dengan asyik sendiri memainkan ponsel.

Seiring berkembang pesatnya kemajuan teknologi saat ini terutama di Indonesia tidak dapat kita pungkiri bahwa penggunaan teknologi sudah merajalela bahkan ke pelosok daerah pun sudah terjamah dengan teknologi. Teknologi yang dulunya sebagai kebutuhan sekunder kini telah menjadi kebutuhan primer, mulai dari kalangan bawah, menengah sampai kalangan atas, anak-anak dan orang tua sudah menggunakan teknologi, dengan berkembangnya teknologi dan disangkutkan dengan pendidikan merupakan hal yang menjadikan suatu revolusioner untuk memajukan pendidikan dengan teknologi

Pemanfaatan teknologi sebagai media pembelajaran yaitu mobile learning yang berbasis android merupak sesuatu yang perlu menjadi pembahasan serta kepedulian pada dunia pendidikan, dimana media android ini memanfaatkan teknologi berupa handphone yang dimiliki guru dan siswa saat ini, sebagai tenaga kependidikan, kita harus jeli melihat perkembangan yang terjadi di masyarakat, apalagi mengenai perkembangan yang terjadi di masyarakat. Mengenai perkembangan teknologi modern saat ini, kita harus memanfaatkan teknologi tersebut sebagai media pembelajaran yang nantinya digunakan oleh tenaga pendidik. Media berbasis android ini menjadi sesuatu yang krusial untuk dapat digunakan dalam pembelajaran yang sejalan dengan data penelitian yang menjunjukkan bahwa ada perbedaan rata-rata hasil belajar untuk pre-test dan post-test pada kelas yang diajarkan dengan mengaplikasikan bahan ajar berbasis android yakni menunjukkan signifikansi $0.039<0.05$ (Wahyuni \& Etfita, 2019). Mobile learning berbasis android juga dapat membantu siswa belajar lebih lama dan focus dan juga percaya diri dalam belajar mandiri (Wibowo \& Arifuddin, 2016)

Pembelajaran yang berlangsung di SMA Unismuh Makassar saat observasi awal, guru masih menggunakan metode ceramah dan penggunaan buku paket dalam proses pembelajaran sehingga siswa kurang tertarik dan lebih memilih untuk melakukan hal-hal lain seperti bercengkrama dengan temannya dan sibuk dengan handphonenya masing-masing.

Berdasarkan latar belakang di atas, sehingga peneliti termotivasi dan tertarik untuk melakukan penelitian dengan judul "Implementasi Media 
Pembelajaran berbasis Android terhadap Hasil Belajar Siswa di SMA Unismuh Makassar".

Adapun rumusan masalah pada penelitian ini adalah apakah ada pengaruh positif yang signifikan antara implementasi pembelajaran berbasis android terhadap hasil belajar siswa di SMA Unismuh Makassar?

Tujuan penelitian ini adalah untuk mengetahui ada tidaknya pengaruh positif yang signifikan antara implementasi media pembelajaran berbasis android terhadap hasil belajar siswa di SMA Unismuh Makassar.

Istilah media berasal dari bahasa Latin yang merupakan bentuk jamak dari "medium" yang secara harafiah berarti perantara atau pengantar. Menurut Arsyad (2014, p. 4) yaitu media pembelajaran adalah segala sesuatu yang dapat digunakan untuk menyampaikan pesan atau informasi dalam proses pembelajaran sehingga dapat merangsang perhatian dan minat siswa dalam belajar. Sedangkan menurut Rusman dkk (2013, p. 170) hakikatnya media pembelajaran sebagai wahana untuk menyampaikan pesan atau informasi dari sumber pesan diteruskan pada penerima. Kemudian Degeng (2013, p. 162) mengemukakan bahwa media pembelajaran adalah komponen strategi penyampaian yang dapat dimuati pesan yang akan disampaikan kepada si-belajar, apakah itu orang, alat, atau bahan. Media pembelajaran merupakan bagian integral dari pembelajaran sehingga proses pembelajaran menjadi lebih bermutu. Penggunaan media dalam pembelajaran diharapkan dapat membuat pembelajaran lebih bermakna. Hal ini sejalan dengan hasil penelitian Nasir (2020) yang berpendapat bahwa dengan mengutamakan penggunaan media dalam pembelajaran akan menimbulkan minat belajar, motivasi belajar, meransang siswa berperan aktif dalam proses pembelajaran.

Android merupakan sistem operasi untuk perangkat mobile yang berbasis Linux dan bersifat terbuka atau opensource dengan lisensi GNU yang dimiliki Google. Ponsel android akan selalu disempurnakan. Tidak seperti sistem tertutup lainnya yang bergantung pada produsen untuk menciptakan inovasi, ini berarti bahwa google maupun mitranya dapat terus membuat penyempurnaan.

Penggunaan smartphone berbasis android diharapkan dapat memberikan variasi untuk siswa dalam belajar, terutama dalam mendapatkan materi yang lebih luas dan mendalam serta kemudahan dalam akses. Hal ini selaras dengan pendapat yang dikemukakan oleh Fatimah dan Mufti (2014) dalam penelitiannya yaitu, media berbasis android membuat pembelajaran lebih menarik, siswa dapat mempelajari materi tanpa terbatas waktu, artinya siswa dapat belajar di luar jam pembelajaran, sehingga akan memberikan dampak positif bagi siswa dalam penggunaan Smartphone sebagai media untuk belajar. Dalam penelitian Muyaroah dan Mega (2017) menunjukkan bahwa pelaksanaan pembelajaran Biologi dengan menggunakan media android lebih efektif dibandingkan dengan pembelajaran Biologi yang tidak menggunakan media android. 
Kegiatan belajar yang akan diperoleh merupakan output atau outcome. Itulah yang dinamakan hasil belajar. Sehingga hasil belajar dapat dijelaskan dengan memahami dua kata yaitu, hasil dan belajar. Pengertian hasil menunjukkan pada suatu perolehan akibat dilakukannya suatu aktivitas atau proses yang mengakibatkan berubahnya input secara fungsional. Dan belajar adalah suatu proses yang kompleks yang terjadi pada semua orang dan berlangsung seumur hidup, sejak dia masih bayi hingga ke liang lahat nanti (Sadiman et al., 2014, p. 2). Menurut Bloom dalam Rahmi dan Khasanah (2019, p. 38) hasil belajar mencakup kemampuan kognitif, afektif dan psikomotorik. Kemampuan psikomotorik meliputi initiatory, preroutine, dan routinized. Sedangkan menurut Sudjana dalam Mawarni dan Nurningsih (2017, p. 95) hasil belajar adalah kemampuan kemampuan yang dimiliki oleh siswa setelah ia menerima pengalaman belajarnya Berdasarkan pengertian diatas maka dapat disimpulkan bahwa hasil belajar adalah suatu penilaian akhir dari rangkaian proses yang telah dilakukan berulang-ulang selama-lamanya karena hasil belajar turut serta dalam membentuk pribadi individu yang selalu ingin mencapai hasil yang lebih baik lagi sehingga akan merubah cara berpikir serta menghasilkan perilaku yang lebih baik.

Adapun hipotesis penelitian berdasarkan uraian kajian Pustaka di atas dan berdasarkan rumusan kajian penelitian ini adalah diduga ada pengaruh positif yang signifikan antara implementasi media pembelajaran berbasis android dengan hasil belajar Bahasa Indonesia siswa di SMA Unismuh Makassar.

\section{METODE}

Metode penelitian ini adalah penelitian deskriptif, menggunakan pendekatan kuantitatif dengan desain korelasional yang bersifat satu arah yaitu mengkaji pengaruh implementasi media pembelajaran berbasis android dengan hasil belajar Bahasa Indonesia siswa di SMA Unismuh Makassar. Dalam penelitian ini yang menjadi variabel penelitian meliputi variabel bebas dan variabel terikat, yang menjadi variabel bebas dalam penelitian ini adalah implementasi pembelajaran berbasis android $(X)$ sedangkan variabel terikat adalah hasil belajar siswa $(\mathrm{Y})$ dengan desain penelitian sebagai berikut:

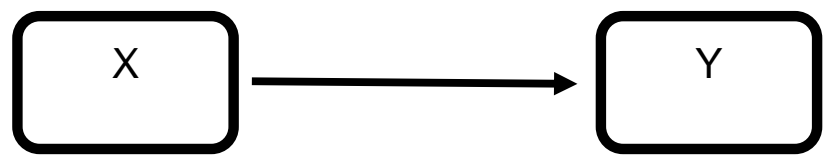

Gambar 1. Desain Penelitian

Pada penelitian ini yang menjadi populasi adalah seluruh siswa SMA Unismuh Makassar yang berjumlah 388 siswa dengan rincian sebagai berikut:

Tabel 1. Keadaan Populasi di SMA Unismuh Makassar 


\begin{tabular}{cccc}
\hline No & Kelas & Jumlah Siswa & Ket \\
\hline 1 & Kelas X & 105 siswa & 3 Kelas \\
2 & Kelas XI & 142 siswa & IPA 2 Kelas \\
& & & IPS 2 Kelas \\
3 & Kelas XII & 141Siswa & IPA 2 Kelas \\
& & & IPS 2Kelas \\
\hline \multicolumn{2}{c}{ Jumlah Siswa } & 388 Siswa & \\
\hline
\end{tabular}

Pengambilan sampel pada penelitian ini menggunakan teknik simple random sampling. Teknik ini dikatakan simple (sederhana) karena pengambilan anggota sampel dari populasi dilakukan secara acak tanpa memperhatikan strata yang ada dalam populasi.

Tabel 2. Keadaan Sampel di SMA Unismuh Makassar

\begin{tabular}{cccc}
\hline No & Kelas & Jumlah Siswa & $\begin{array}{c}\text { Jumlah Siswa } \\
\text { (random sampling) }\end{array}$ \\
\hline 1 & $\mathrm{X}$ & 105 & 13 \\
2 & $\mathrm{XI}$ & 142 & 18 \\
3 & $\mathrm{XII}$ & 141 & 18 \\
\hline Jumlah Siswa & 388 & 49 \\
\hline
\end{tabular}

Instrumen pengumpulan data yang digunakan dalam penelitian ini yaitu kuesioner (angket) dan tes hasil belajar. Angket digunakan untuk mendapatkan data tentang respon siswa menggunakan media android dalam proses pembelajaran dan tes hasil belajar digunakan untuk mengukur kemampuan siswa dalam mencapai tujuan pembelajaran pada materi yang diajarkan menggunakan media android. Analisis data yang digunakan dalam penelitian ini adalah deskriptif dan inferensial. Untuk menggambarkan implementasi pembelajaran berbasis android dan hasil belajar Bahasa Indonesia siswa di SMA Muhammadiyah Unismuh Makassar, maka digunakan rumus presentase.

$$
\begin{aligned}
& P=\frac{f}{N} \times 100 \\
& \text { Keterangan : } \\
& \mathrm{P} \quad=\text { Presentase } \\
& f \quad=\text { Frekuensi yang dicari persentasenya } \\
& \mathrm{N} \quad=\text { Jumlah responden }
\end{aligned}
$$

Analisis korelasi product moment dimaksudkan untuk menguji ada tidaknya pengaruh dan taraf signifikansi antara kedua variabel, yaitu implementasi pembelajaran berbasis android dengan hasil belajar siswa di SMA Muhammadiyah Unismuh Makassar dengan rumus sebagai berikut: 


$$
\mathbf{r}_{\mathrm{xy}}=\frac{\sum \mathrm{XY}}{\sqrt{\left(\sum \mathrm{x}^{2}\right)\left(\Sigma \mathrm{Y}^{2}\right)}} \quad \text { (Trijono, 2015, p. 70) }
$$

$$
\begin{aligned}
& \text { Keterangan: } \\
& \begin{array}{ll}
r_{x y} & =\text { Koefisien korelasi } \\
\mathrm{X}^{2} & =\text { Skor variable } \mathrm{X}^{2} \\
\mathrm{Y}^{2} & =\text { Skor variable } \mathrm{Y}^{2}
\end{array}
\end{aligned}
$$

Guna mengetahui besarnya pengaruh antara kedua variabel, maka digunakan patokan interpretasi nilai $r$ sebagai berikut:

Tabel 3. Interpretasi Koefisien Korelasi

\begin{tabular}{ll}
\hline Interval Koefisien $r$ & Tafsiran/Analisa \\
\hline $0,00-0,199$ & Sangat rendah \\
$0,20-0,399$ & Rendah \\
$0,40-0,599$ & Sedang \\
$0,60-0,799$ & Kuat \\
$0,80-1,000$ & Sangat kuat
\end{tabular}

Sumber: (Sugiyono, 2015, p. 257)

\section{HASIL}

Penelitian mengenai implementasi media pembelajaran berbasis android terhadap hasil belajar Bahasa Indonesia siswa di SMA Muhammadiyah Unismuh Makassar dengan menggunakan angket dan tes terhadap 49 responden, selanjutnya hasil angket tersebut dianalisis menggunakan analisis presentase dan dengan tabel frekuensi untuk memudahkan dalam memahami penelitian tersebut dideskripsikan. Dalam angket terdiri dari 10 item pernyataan dimana setiap item tertinggi diberi skor 5 dan skor terendah 1 dengan jumlah responden 49 dengan demikian skor yang tertinggi adalah (skor ideal) 40 (10x4) dan skor terendah 10

\begin{tabular}{|c|c|c|c|}
\hline Interval & Kategori & Frekuensi & Persentase \\
\hline $34-40$ & Sangat Tinggi & 46 & 93,87 \\
\hline $26-33$ & Tinggi & 3 & 6,13 \\
\hline $18-25$ & Sedang & 0 & 0 \\
\hline $10-17$ & Rendah & 0 & 0 \\
\hline \multicolumn{2}{|c|}{ Jumlah } & 49 & 100,00 \\
\hline
\end{tabular}
(10x1) dengan interval skor 7 . Lebih jelasnya mengenai gambaran implementasi media pembelajaran berbasis android, dapat dilihat pada tabel distribusi frekuensi dan persentase berikut.

Tabel 4. Distribusi Frekuensi dan Persentase Implementasi Media Android 
Berdasarkan data hasil pengisian kuesioner di atas menunjukkan bahwa yang tergolong dalam kategori sangat tinggi sebanyak 46 responden dengan persentase 93,87 persen. Kemudian disusul kategori tinggi sebanyak 3 responden dengan persentase 6,13 persen. Dari hasil angket menunjukkan bahwa implementasi media android sudah terlaksana secara baik dibuktikan dengan respon siswa sebesar 93,87 persen berada pada interval kategori tinggi.

Hasil belajar siswa dibagi atas empat kategori yaitu sangat tinggi, tinggi, sedang dan rendah. Tes hasil belajar terdiri dari 10 nomor pertanyaan essay, dengan skor ideal tiap item 5 dan skor terendah 1 . Untuk skor tertinggi $10 \times 5=50$ dan skor terendah $10 \times 1=10$. Untuk lebih jelasnya dapat dilihat pada tabel distribusi frekuensi dan persentase berikut.

Tabel 5. Distribusi Frekuensi dan Persentase Hasil Belajar Siswa

\begin{tabular}{cccc}
\hline Interval & Kategori & Frekuensi & Persentase \\
\hline $40-50$ & Sangat Tinggi & 49 & 100 \\
$30-39$ & Tinggi & 0 & 0 \\
$20-29$ & Sedang & 0 & 0 \\
$10-19$ & Rendah & 0 & 0 \\
\hline & Jumlah & 49 & 100,00 \\
\hline
\end{tabular}

Berdasarkan data tes hasil belajar di atas menunjukkan bahwa semua siswa tergolong dalam kategori sangat tinggi dengan persentase 100 persen. Dari tes hasil belajar menunjukkan bahwa skor hasil belajar siswa yaitu 44,93 yang berada pada interval $40-50$ dengan kategori sangat tinggi. Hal ini berarti hasil belajar menggunakan media android sangat baik.

Hipotesis penelitian ini adalah diduga ada pengaruh yang signifikan antara implementasi media pembelajaran androind dengan hasil belajar siswa di SMA Muhammadiyah Unismuh Makassar. Uji hipotesis untuk mengetahui apakah variabel bebas $(X)$ memiliki pengaruh positif yang signifikan atau tidak dengan variabel terikat $(\mathrm{Y})$ dapat diketahui dengan kriteria pengujian:

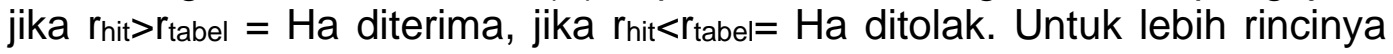
dapat dilihat pada uraian berikut.

Tabel 6. Data Penelitian implementasi media android $(\mathrm{X})$ dan variabel hasil belajar $(Y)$

\begin{tabular}{cccccc}
\hline No Res & $\mathbf{X}$ & $\mathbf{Y}$ & $\mathbf{X 2}$ & $\mathbf{Y 2}$ & $\mathbf{X Y}$ \\
\hline 1 & 35 & 46 & 1225 & 2116 & 1610 \\
2 & 35 & 44 & 1225 & 1936 & 1540 \\
3 & 35 & 46 & 1225 & 2116 & 1610 \\
4 & 34 & 44 & 1156 & 1936 & 1496 \\
5 & 35 & 47 & 1225 & 2209 & 1645 \\
6 & 37 & 45 & 1369 & 2025 & 1665 \\
7 & 37 & 48 & 1369 & 2304 & 1776
\end{tabular}




\begin{tabular}{cccccc}
\hline No Res & $\mathbf{X}$ & $\mathbf{Y}$ & $\mathbf{X 2}$ & $\mathbf{Y 2}$ & $\mathbf{X Y}$ \\
\hline 8 & 36 & 48 & 1296 & 2304 & 1728 \\
9 & 33 & 43 & 1089 & 1849 & 1419 \\
10 & 37 & 47 & 1369 & 2209 & 1739 \\
11 & 39 & 44 & 1521 & 1936 & 1716 \\
12 & 36 & 45 & 1296 & 2025 & 1620 \\
13 & 38 & 45 & 1444 & 2025 & 1710 \\
14 & 36 & 44 & 1296 & 1936 & 1584 \\
15 & 36 & 43 & 1296 & 1849 & 1548 \\
16 & 34 & 44 & 1156 & 1936 & 1496 \\
17 & 34 & 42 & 1156 & 1764 & 1428 \\
18 & 34 & 45 & 1156 & 2025 & 1530 \\
19 & 36 & 46 & 1296 & 2116 & 1656 \\
20 & 35 & 43 & 1225 & 1849 & 1505 \\
21 & 34 & 46 & 1156 & 2116 & 1564 \\
22 & 35 & 42 & 1225 & 1764 & 1470 \\
23 & 35 & 46 & 1225 & 2116 & 1610 \\
24 & 34 & 45 & 1156 & 2025 & 1530 \\
25 & 36 & 45 & 1296 & 2025 & 1620 \\
26 & 35 & 41 & 1225 & 1681 & 1435 \\
27 & 33 & 46 & 1089 & 2116 & 1518 \\
28 & 35 & 42 & 1225 & 1764 & 1470 \\
29 & 35 & 44 & 1225 & 1936 & 1540 \\
30 & 37 & 42 & 1369 & 1764 & 1554 \\
31 & 34 & 47 & 1156 & 2209 & 1598 \\
32 & 32 & 44 & 1024 & 1936 & 1408 \\
33 & 34 & 46 & 1156 & 2116 & 1564 \\
34 & 35 & 44 & 1225 & 1936 & 1540 \\
35 & 34 & 45 & 1156 & 2025 & 1530 \\
36 & 36 & 44 & 1296 & 1936 & 1584 \\
37 & 35 & 45 & 1225 & 2025 & 1575 \\
38 & 35 & 47 & 1225 & 2209 & 1645 \\
39 & 36 & 44 & 1296 & 1936 & 1584 \\
40 & 36 & 47 & 1296 & 2209 & 1692 \\
41 & 35 & 45 & 1225 & 2025 & 1575 \\
42 & 34 & 47 & 1156 & 2209 & 1598 \\
43 & 35 & 45 & 1225 & 2025 & 1575 \\
44 & 36 & 47 & 1296 & 2209 & 1692 \\
45 & 35 & 45 & 1225 & 2025 & 1575 \\
46 & 37 & 45 & 1369 & 2025 & 1665 \\
47 & 35 & 45 & 1225 & 2025 & 1575 \\
48 & 36 & 47 & 1296 & 2209 & 1692
\end{tabular}

Implementasi media pembelajaran | 8 


\begin{tabular}{cccccc}
\hline No Res & $\mathbf{X}$ & $\mathbf{Y}$ & $\mathbf{X 2}$ & $\mathbf{Y 2}$ & $\mathbf{X Y}$ \\
\hline 49 & 34 & 45 & 1156 & 2025 & 1530 \\
\hline Jumlah & $\mathbf{1 7 2 5}$ & $\mathbf{2 2 0 2}$ & $\mathbf{6 0 8 0 9}$ & $\mathbf{9 9 0 8 6}$ & $\mathbf{7 7 5 2 9}$ \\
\hline
\end{tabular}

Data di atas kemudian dimasukkan ke rumus korelasi product moment sebagai berikut:

$$
\begin{aligned}
& r_{x y}=\frac{\sum X Y}{\sqrt{\left(\sum X^{2}\right)\left(\sum Y^{2}\right)}} \\
& r_{x y}=\frac{77529}{\sqrt{(60809)(99086)}} \\
& r_{x y}=\frac{77529}{\sqrt{6025320}} \\
& r_{x y}=\frac{77529}{77662,93} \\
& r_{x y}=0,998
\end{aligned}
$$

Berdasarkan perhitungan dengan korelasi product moment maka diperoleh nilai $r$ sebesar 0,998 sedangkan nilai rtabel pada taraf signifikansi 5 persen dengan N 49 sebesar 0,281 (Sugiyono, 2014, p. 333). Karena nilai rhitung lebih besar dari pada nilai rtabel, maka hipotesis alternatif yaitu (Ha) "Ada pengaruh positif yang signifikan impelementasi media pembelajaran android terhadap hasil belajar Bahasa Indonesia siswa SMA Muhammadiyah Unismuh Makassar", dinyatakan diterima. Hasil perhitungan korelasi product moment menunjukkan rhitung lebih besar dari pada nilai rtabel, maka dapat dinyatakan bahwa kedua variabel terdapat pengaruh, bahkan pengaruhnya sangat kuat karena berada pada interval $0,80-1,000$.

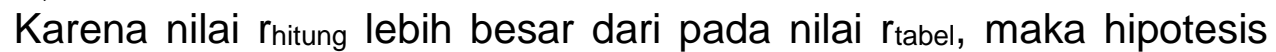
alternatif yaitu $(\mathrm{Ha})$ "Ada pengaruh yang positif signifikan impelementasi media pembelajaran android terhadap hasil belajar Bahasa Indonesia siswa SMA Muhammadiyah Unismuh Makassar", dinyatakan diterima. Hal ini menunjukkan bahwa optimalnya implementasi media android pada proses pembelajaran, akan berdampak baik pada hasil belajar siswa. Selanjutnya menghitung koefisien determinasi untuk mengetahui seberapa besar implementasi media pembelajaran berbasis android $(X)$ berpengaruh terhadap hasil belajar siswa $(\mathrm{Y})$. Adapun perhitungan Koefisien Determinasi (KD) yaitu dengan cara mengkuadratkan koefisien yang ditemukan (Sugiyono, 2015, p. 259).

$$
\begin{aligned}
\mathrm{KD} & =\mathrm{r}^{2} \\
& =0,998^{2} \\
& =0,996004
\end{aligned}
$$


$=99,60 \%$

Jadi, konstribusi implementasi media pembelajaran berbasis android $(X)$ terhadap hasil belajar siswa $(Y)$ sebesar $99,60 \%$. Dengan merujuk pada hasil penelitian ini, jika dalam pembelajaran media android dimanfaatkan secara baik dan benar maka akan sangat berkontribusi pada hasil belajar.

\section{PEMBAHASAN}

Berdasarkan hasil penelitian yang diuraikan di atas, menunjukkan bahwa implementasi media pembelajaran berbasi android berada pada pada interval dengan kategori sangat tinggi dan tinggi. Hal ini berarti siswa sangat antusias menggunakan media android sebagai media baru dalam proses pembelajaran. Hasil tes belajar siswa setelah menggnunakan media android menujukkan seluruh responden berada pada kategori sangat tinggi. Artinya, jika media android dimanfaatkan dengan baik dan benar sesuai kebutuhan maka akan memengaruhi hasil belajar siswa.

Pengujian hipotesis menggunakan korelasi product moment, dapat diketahui nilai rhitung lebih besar dibandingkan dengan rabel pada taraf siginifikasi lima persen. Dari hasil tersebut Hipotesis Alternatif $(\mathrm{Ha})$ yang menyatakan bahwa ada pengaruh positif yang signifikan implementasi media pembelajaran berbasis android terhadap hasil belajar siswa di SMA Muhammadiyah Unismuh Makassar dinyatakan diterima dan Hipotesis Nihil (Ho) yang menyatakan tidak ada pengaruh positif yang signifikan implementasi media pembelajaran berbasis android terhadap hasil belajar siswa di SMA Muhammadiyah Unismuh Makassar dinyatakan ditolak. Berarti terdapat pengaruh positif yang signifikan antara variabel $X$ dan variabel $Y$ bahkan korelasinya berada pada interval dengan kategori korelasi sangat kuat. Konstribusi implementasi media pembelajaran berbasis android $(\mathrm{X})$ terhadap hasil belajar siswa $(\mathrm{Y})$ sesuai dengan perhitungan koefisien determinasi sebesar 99,60 persen dan sisanya ditentukan oleh variabel lain yang tidak diteliti sebesar 0,4 persen. Hasil penelitian berbasis android juga dilakukan oleh Kartini \& Putra (2020) yang menunjukkan bahwa hasil belajar siswa dipengaruhi oleh media pembelajaran interaktif berbasis android sebesar $62,72 \%$. Kemudian hasil penelitian lainnya juga menunjukkan hasil yang positif antara penggunaan media 3D science berbasis android terhadap hasil belajar Biologi siswa yang menunjukkan nilai thitung $=13.380$ lebih besar dari ttabel $=1,66$ dengan taraf signifikan 0,05 atau 5\% (Kalsum, 2020).

Dengan demikian, hasil penelitian di atas merupakan suatu penegasan pentingnya peran suatu media dalam proses pembelajaran guna lebih memerinci, memperluas, meperdalam materi pelajaran, dan tentunya memudahkan pendidik dalam menyampaikan materi yang disajikan. Dengan cara memanfaatkan berbagai media dalam pembelajaran, berarti tingkat kemampuan siswa dalam mendalami materi pelajaran akan semakin maksimal yang mana hal ini akan berdampak secara langsung pada hasil hasil belajar siswa. Media android sangat lekat pada kehidupan sehari-hari remaja SMA yang berfungsi sebagai alat 
komunikasi dan sangat berpotensi sebagai media pembelajaran yang inovatif dan interaktif bagi siswa (Aris et al., 2021).

\section{KESIMPULAN}

Berdasarkan hasil penelitian dan hasil pengujian hipotesis yang telah dilakukan, maka dapat ditarik kesimpulan bahwa terdapat pengaruh yang positif dan signifikan antara implementasi media pembelajaran berbasis android terhadap hasil belajar Mata Pelajaran Bahasa Indonesia siswa di SMA Muhammadiyah Unismuh Makassar. Yang berarti Hipotesis Alternatif $(\mathrm{Ha})$ diterima dan Hipotesis Nihil $(\mathrm{Ho})$ ditolak. Dengan demikian dengan menggunakan media berbasis android dapat menjadi khazanah baru dalam penggunaan media pembelajaran pada mata pelajaran lain mengingat hampir semua kalangan usia sudah pandai menggunakan ponsel pintar berbasis android.

\section{SARAN}

Berdasarkan hasil penelitian, pembahasan dan kesimpulan, kesimpulan maka penulis menyarankan agar : 1) Implementasi media pembelajaran berbasis android hendaknya dapat diimplementasikan sebagai media belajar baru yang efektif kegunaannya untuk meningkatkan hasil belajar siswa; 2) Bagi tenaga pengajar, untuk memperbarui penggunaan media pembelajaran yang menarik dan inovatif agar siswa tidak merasa bosandalam pembelajaran; 3) Perlu adanya kerjasama antara tenaga pengajar, tenaga kependidikan, siswa, dan pihak lainnya untuk meningkatkan mutu pendidikan di sekolah.

\section{DAFTAR PUSTAKA}

Aris, M., Dzuliman, M., Gazali, E., \& Kusnawati, Y. (2021). Penerapan Media Pembelajaran Bahasa Arab Berbasis Android di MA Salafiyah Kota Cirebon. EL-IBTIKAR: Jurnal Pendidikan Bahasa Arab, 9(2), 130-152.

Arsyad, A. (2014). Media Pembelajaran. PT. Raja Grafindo Persada.

Degeng, N. S. (2013). Ilmu Pembelajaran (Klasifikasi Variabel untuk Pengembangan Teori dan Penelitian. Aras Media.

Fatimah, S., \& Mufti, Y. (2014). Pengembangan media pembelajaran IPAFisika smartphone berbasis android sebagai penguat karakter sains siswa. Jurnal Kaunia, 10(1), 59-64. http://ejournal.uinsuka.ac.id/saintek/kaunia/article/view/1066

Kalsum. (2020). Pengaruh Penggunaan Media 3d Sience Berbasis Android Dengan Model Pembelajaran Kooperatif Terhadap Hasil Belajar Biologi Siswa Kelas Viii Di Mts Negeri 1 Maros Baru. Jurnal Binomial, 3(1), 49-60. 
Kartini, K. S. dan, \& Putra, I. N. T. . (2020). Pengaruh Penggunaan Media Pembelajaran Interaktif Berbasis Android Terhadap Hasil Belajar Siswa. Redoks: Jurnal Pendidikan Kimia Dan Ilmu Kimia, 3(02), 8-12.

Marwani, L., \& Nurningsih, S. (2017). Pengaruh Model Pembelajaran Elaborasi Dengan Berpikir Kreatif Terhadap Hasil Belajar Tematik Bahasa Indonesia. Akademika, 6(2), 91-104.

Muyaroah, S., \& Fajartia, M. (2017). Pengembangan Media Pembelajaran Berbasis Android dengan menggunakan Aplikasi Adobe Flash CS 6 pada Mata Pelajaran Biologi. Innovative Journal of Curriculum and Educational Technology, $6(2)$, 79-83. https://doi.org/10.15294/ijcet.v6i2.19336

Nasir. (2020). Pengembangan Media Pembelajaran Pendidikan Agama Islam (Pai) Berbasis Web Di Kelas Viii Smp Unismuh Makassar. Akademika, $9(01)$, 127-138. https://doi.org/10.34005/akademika.v9i01.813

Rahmi, D., \& Khasanah. (2019). Pengaruh Model Problem Based Learning Dan Kreativitas Belajar Terhadap Hasil Belajar Prakarya Dan Kewirausahaan. Akademika Jurnal Teknologi Pendidikan, 8(1), 3545.

Rusman, Kurniawan, D., \& Riyana, C. (2013). Pembelajaran Berbasis Teknologi Informasi dan Komunikasi. PT. Raja Grafindo Persada.

Sadiman, A. S., Rahardjo, R., Haryono, A., \& Harjito. (2014). Media Pendidikan: Pengertian, Pengembangan, dan Pemanfaatannya. PT. Raja Grafindo Persada.

Sugiyono. (2014). Metode Penelitian Kuantitatif, Kualitatif, dan $R \& D$. Alfabeta.

Sugiyono. (2015). Metode Penilitian Pendidikan. Alfabeta.

Trijono, R. (2015). Metodologi Penelitian Kuantitatif. Papas Sinar Sinanti.

Wahyuni, S., \& Etfita, F. (2019). Efektivitas Bahan Ajar Berbasis Android Terhadap Hasil Belajar. GERAM (GERAKAN AKTIF MENULIS), 7(2), 44-49.

Wibowo, E. A., \& Arifuddin, R. (2016). Aplikasi Mobile Learning Berbasis Android. UNNES Journal of Mathematics, 5(2), 108-117. 